\title{
De la ambigüedad avant toute chose: humor y reescritura en el teatro de José Sanchis Sinisterra
}

\author{
RENATA LONDERO \\ Università di Udine
}

Título: De la ambigüedad avant toute chose: humor y reescritura en el teatro de José Sanchis Sinisterra.

Resumen: A partir de las ideas de frontera y de ambigüedad, fundamentales en la estética dramática de José Sanchis Sinisterra (Valencia, 1940), el presente artículo sondea de qué manera el humorismo -basado en el "sentimiento de lo contrario" de Pirandello, y por lo tanto en la contigüidad entre lo cómico y lo trágico- se expresa en cinco obras significativas del autor. Se trata de Naque (1980), ;Ay, Carmela! (1987), "Atajo" (en Terrory miseria en el primer franquismo, 2002), Misiles melódicos (2004) y Vagas noticias de Klamm (2009). La sonrisa o la risa amarga de Sanchis se aplican a argumentos serios o graves (la difícil condición del actor, la Guerra civil espanola, el franquismo, la desigualdad en el mundo, el desempleo) en estas piezas que también resultan liminares desde el punto de vista genérico. De hecho, en su mayoría son hipertextos lúdicos que emplean recursos típicos del pastiche, de la parodia o de la caricatura, a nivel tanto temático como estilístico, con la finalidad de manifestar la naturaleza difuminada y ambivalente de la experiencia humana.

Palabras clave: Sanchis Sinisterra, Teatro, Reescritura, Humor, Parodia.

Fecha de recepción: 25/2/2021.

Fecha de aceptación: 27/5/2021.
Title: Ambiguity avant toute chose: Humour and Re-writing in José Sanchis Sinisterra’s Drama

Abstract: Starting from the ideas of border and ambiguity, fundamental in the dramatic aesthetics of José Sanchis Sinisterra (Valencia, 1940), this essay deepens how the humour -based on Pirandello's "feeling of the opposite" and on the closeness of the comic and the tragic as a consequence- shows itself in five significant plays by the author. They are the following: Naque (1980), ¡Ay, Carmela! (1987), "Atajo” (in Terror $y$ miseria en el primer franquismo, 2002), Misiles melódicos (2004) and Vagas noticias de Klamm (2009). Sanchis's bitter smile or laugh applies to serious or even tragic topics (the actor's difficult life, the Spanish civil war, Franquism, the world's inequality, unemployment) in the above-mentioned works, which are borderline as far as their genre is concerned as well. In fact, most of them are playful hypertexts using forms typical of pastiche, parody and caricature, both on a thematic and (above all) stylistic level, with the purpose of expressing the blurred and ambivalent nature of human experience.

Key words: Sanchis Sinisterra, Theatre, Rewriting, Humour, Parody.

Date of Receipt: 25/2/2021.

Date of Approval: 27/5/2021. 
En "El espectador ideal”, un artículo de $2015^{1}$ donde José Sanchis Sinisterra condensa magistralmente los cimientos de su estética fronteriza, aparecen cuatro conceptos en los que también se fundamentan la teoría y la praxis del humor en su teatro: caos, polisemia, interacción, capacidad crítica. En un mundo incomprensible e imprevisible, sumido en el desorden y la incertidumbre, el dramaturgo valenciano "escoge el límite como su materia", para traspasarlo continuamente, cultivando el mestizaje y el hibridismo genérico, semiótico, estilístico y lingüístico, sin dejar de interpelar a un público activo que indague, reflexione, opine ${ }^{3}$.

Ahora bien: ¿la raíz principal del humorismo y de la comicidad -en la estela de Bergson ${ }^{4}$ y de Pirandello ${ }^{5}-$, no es, quizá, la complejidad de nuestra experiencia, a la vez trágica y cómica, emotiva y racional, que se manifiesta a través del "sentimiento de lo contrario" alumbrado por el intelecto? De ahí que la "risa reflexiva" que Sanchis Sinisterra pretende suscitar en sus espectadores ${ }^{6}$ se desprenda de su concepción del humor como "una herramienta intelectual [...], un modo de contemplar [y] [...] de transmitir" la condición humana, desacralizándola ${ }^{7}$. Además, puesto que la risa y la sonrisa con frecuencia derivan de la desgracia y del sufrimiento, muchas formas del humor — como la ironía, la parodia y la sátira- destacan por la ambivalencia de sus matices ${ }^{8}$, es decir, por su naturaleza difuminada y

1 José Sanchis Sinisterra, "El espectador ideal”, Ínsula, 823-824 (2005), pp. 50-56.

2 Juan Mayorga, "Romper el horizonte: la misión de José Sanchis Sinisterra", en José Sanchis Sinisterra, La escena sin limites. Fragmentos de un discurso teatral, ed. Manuel Aznar Soler, Ciudad Real, Naque, 2002, pp. 25-28 (p. 25).

3 Para una síntesis sobre la sustancia fronteriza de la visión de lo real y lo teatral en el autor, remito a Renata Londero, "Introduzione", en José Sanchis Sinisterra, El lector por horas/Il lettore a ore, ed. y trad. Renata Londero, Pisa, ETS, 2018, pp. 7-28.

4 Henri Bergson, Le rire: essai sur le signification du comique, Paris, Félix Alcan, 1900.

5 Luigi Pirandello, Lumorismo, Lanciano, Rocco Carabba Editore, 1908.

6 Simone Trecca, "Los niveles de humor en La raya del pelo de William Holden, de José Sanchis Sinisterra", en El teatro de humor en los inicios del siglo XXI, ed. José Romera Castillo, Madrid, Visor, 2010, pp. 415-432 (p. 425).

7 Respuesta de Sanchis Sinisterra en la entrevista que le hizo Juan Antonio Ríos Carratalá en la Universidad de Alicante, el 11 de noviembre de 2005, en Biblioteca Virtual Miguel de Cervantes: www.cervantesvirtual.com (consultada el 30/12/2020).

8 Sobre la esencia dúplice de la ironía, pueden verse: Vladimir Jankélévitch, La ironía (1964), prólogo de Javier Gomá, trad. Ricardo Pochtar, Madrid, Taurus, 2020; 
translúcida, como la llamaría Sanchis. En particular, en el ámbito de lo lúdico, nuestro comediógrafo, aficionado a cruces, injertos y reescrituras, privilegia géneros hipertextuales ambiguos como el pastiche y la parodia ${ }^{9}$, que imitan o transforman sus modelos censurándolos y rindiéndoles homenaje al mismo tiempo, en una constante relación dialéctica con ellos ${ }^{10}$. Una análoga preferencia por lo antitético y lo tragicómico se da tanto en la selección de las situaciones dramáticas como en la caracterización psicológica de los personajes: por lo general Sanchis logra los efectos humorísticos más eficaces cuando lleva a cabo una acción cargada de patetismo o ridiculiza a figuras desdichadas y marginales o más bien despreciables. Así ocurre con el Paulino de jAy, Carmela! (1987), y Ríos y Solano en Naque (1980) por un lado, y por otro con Abundio y Bolonio en "Atajo" (Terror $y$ miseria en el primer franquismo, 2002), con Javier Zulueta — protagonista de Misiles melódicos (2004-2005)_, y con el Señor Valverde de Vagas noticias de Klamm (2009). De hecho, este es el pequeńo, aunque (creo) significativo corpus textual que he elegido para ilustrar las diversas facetas y modalidades del humor según Sanchis Sinisterra.

Empecemos por la obra más conocida, representada y traducida del autor: ¡Ay, Carmela!, que se estrenó el 5 de noviembre de 1987 en el Teatro Principal de Zaragoza, y cuyo éxito internacional dio pie a la única y afortunada adaptación cinematográfica del teatro de Sanchis, la película homónima dirigida en 1990 por Carlos Saura y protagonizada por los extraordinarios Carmen Maura y Andrés Pajares. Como mantiene Manuel Aznar Soler en su edición de la pieza (1997), esta "Elegía de una guerra civil en dos actos y un epílogo", según reza el subtítulo, está marcada por la dualidad ${ }^{11}$, en el tiempo, en el espacio, en el conflicto entre vida

Marina Mizzau, L'ironia. La contraddizione consentita, Milano, Feltrinelli, 1984; Linda Hutcheon, Irony's Edge: The Theory and Politics of Irony, London and New York, Routledge, 1994.

9 Gérard Genette, Palimpsestos. La literatura en segundo grado (1982), trad. Celia Fernández Prieto, Madrid, Taurus, 1989, passim, sostiene que todo hipertexto está basado en la ambigüedad de su lectura e interpretación, como obra autónoma pero también dependiente del/de los hipotexto/s.

10 Mirella Billi, Il testo riflesso. La parodia nel romanzo inglese, Napoli, Liguori, 1993, p. 35, define la parodia como "un dialogo critico tra testi".

11 Manuel Aznar Soler, "Introducción”, en José Sanchis Sinisterra, Naque-jAy, Carmela!, ed. Manuel Aznar Soler, Madrid, Cátedra, 1997, pp. 11-103 (p. 66). 
y muerte, ficción y realidad histórica, y en el entramado expresivo, que es el aspecto que más nos interesa realzar aquí. En tal ámbito, son dos los rasgos privativos del discurso de Carmela y Paulino que enfatizan su fuerza cómica: la gran cantidad de equívocos y dobles sentidos (sobre todo de tipo sexual) — frecuentes resortes de la risa- ${ }^{12}$, y el habilísimo aprovechamiento del registro coloquial, que comparte su carácter conciso y elíptico con la tendencia a la compresión y a la sustracción tanto de la ironía en general como del lenguaje empleado por Sanchis en su escritura dramática: lacónico, reticente y sembrado de pausas y silencios ${ }^{13}$.

En primer lugar, el cobarde Paulino esgrime un entretenido itañol para congraciarse con el teniente fascista Amelio Giovanni de Ripamonte, como se ve en la cita siguiente: "Cosa male fare arte cosí, spogliati, smantellati, smirriati... ¿Non è vero? È verissimo, mi teniente, no me lo niegue ... Usted lo sabe muy bien, como artista que es, italiano además, de la cuna del arte ... Italia, ahí es nada: Miguel Ángel, Dante, Petrarca, Puccini, Rossini, Boccherini, Mussolini ..."14. Además, resultan hilarantes muchos casos de dilogía, a menudo vinculados con el tabú del sexo. Por ejemplo, mientras están ensayando la velada patriótica pronacionalista en el teatro de Belchite, a la que asistirán al día siguiente los milicianos extranjeros condenados a muerte, la veraz Carmela no deja de exhibir su rabioso desacuerdo, y protesta por su burdo traje de escena, confeccionado con unas cortinas. Sigue la respuesta de Paulino, tenso frente a Ripamonte, y luego la réplica enfadada de su compañera: "PAULino. [...] De verdad que estás muy salerosa... / CARMELA. El salero te lo iba a meter yo por la boca..." ${ }^{15}$. Divierte el juego entre las dos acepciones -estándar e informal — de "salero", como "recipiente destinado a contener sal” y como "gracia" 16 . Genera más comicidad aún un pasaje del segundo acto, que gira alrededor del doble significado del término "conejo", el

12 Aznar Soler, ibidem, p. 86, habla de "comicidad fundamentalmente verbal" con respecto a esta pieza (ibidem, p. 86).

13 Para Jankélévitch, op. cit., p. 99, "el silencio, la reticencia y la alusión configuran el singular perfil de la ironía. La ironía es lacónica. [...] su estilo es más elíptico que enciclopédico", puesto que está dominada por la lítote.

14 Sanchis Sinisterra, Naque-jAy, Carmela!, acto I, p. 202.

15 Ibidem, acto I, p. 200.

16 Manuel Seco, Olimpia Andrés y Gabino Ramos, Diccionario del español actual, Madrid, Aguilar, 1999, II, p. 4012. 
referencial (que designa al animal) y el vulgar, referido al órgano sexual femenino:

CARMEla. Mira que te lo tengo dicho: no abuses del conejo.

PAULINO. ¿Qué?

CARMEla. Siempre te sienta mal. Y peor con los nervios de antes de empezar.

PAULINO. ¿De qué hablas?

CARMELA. ¿A quién se le ocurre merendarse con un conejo entero, a menos de dos horas de una función que ni Dios sabe cómo nos va a salir? [...]

En cambio, los juegos de palabras a los que recurren los dos actores durante el espectáculo en abyme a lo largo del segundo acto, no solo funcionan como móviles de humor verbal, sino que también remiten a una comicidad situacional chocante ${ }^{17}$ : la actuación de los incómodos Paulino y Carmela ante el auditorio de militares nacionalistas entra en conflicto con su propia condición anímica y existencial, condicionada por el terror del fusilamiento. Dos ejemplos in crescendo pueden bastar al respecto. En primer lugar, al comienzo del espectáculo, Paulino traspapela los folios del guion, de manera que en vez de una bienvenida captadora lee nada menos que una lista de la compra, traicionando su nervioso malestar:

PaUlino. Invictos salvadores de la Patria eterna: [...] nuestro egre... sí, nuestro egregio, eso, egregio Caudillo Franco, a quien esta noche queremos ofrendar ... [...] cuatro kilos de morcillas, dos pares de ligas negras, dos docenas de ... [...] No, perdón ... [...] Queremos ofrendar ... ofrendar ... ¡Aquí está! [...] Queremos ofrendar esta sencilla Velada Artística, Patriótica y Recreativa [... $]^{18}$.

No obstante, el clímax grotesco y trágico del texto se alcanza cuando la pareja protagonista interpreta a su pesar la tosca farsa arrevistada en contra de la Segunda República, "El Doctor Toquemetoda", donde la República/Carmela acude al consultorio del médico/Paulino para que le

17 Acerca del humorismo verbal y de situación, puede leerse a Pierre Schoentjes, $\mathrm{La}$ poética de la ironía, Madrid, Cátedra, 2003 [2001].

18 Sanchis Sinisterra, Naque-jAy, Carmela!, op. cit., acto II, pp. 232-233. 
cure su enfermedad (acto II) ${ }^{19}$. La pantomima está cuajada de dilogías sexuales, como la del termómetro/pene:

PaUlino. Y usted, ¿qué es lo que tiene?

CARMELa. ¿Yo? Calenturas.

PAUlino. Vaya vaya... Conque calenturas...

CARMELA. Sí, doctor: calenturas. Póngame usted su termómetro, y

las notará.

PaUlino. Pues es que resulta que tengo el termómetro... estropeado.

CARMELA. Usted póngamelo, y verá cómo se lo hago funcionar ${ }^{20}$.

Y cuanto más groseras se hacen las alusiones carnales ${ }^{21}$, más se acerca el funesto final _ el asesinato de la rebelde Carmela en las tablas_-, anticipado por el lamentable número de los pedos — la "vergüenza del artista"-, que un desesperado Paulino realiza "para intentar salvarla haciéndola cómplice de su parodia" 22 .

"Lo trágico y lo cómico mezclado" ya se había propuesto unos años antes en Naque o de piojos y actores, "mixtura joco-seria de garrufos varios" 23 que se escenificó por primera vez el 29 de octubre de 1980 en el Festival de Teatre de Sitges ${ }^{24}$. En esta pieza, Sanchis otra vez pone en práctica de manera brillante su habitual estrategia reelaboradora (la "dramaturgia cohesiva”, como él la denomina), creando un pastiche lúdico, literario/ lingüístico ${ }^{25}$, que a través del dúo de Ríos y Solano —a medio camino

19 Ibidem, pp. 247-252.

20 Ibidem, pp. 249-250.

21 Se trata de las siguientes: "un resbalón abrileño", "la mala leche" que pasó una nodriza a la República, sus "manchas rojas en la piel", y el hecho de que para "darle remedio [...] unos se lo daban por delante ... y otros [...] por detrás” (ibidem, pp. 250-251).

22 Ibidem, p. 251 (penúltima acotación del acto II).

23 Son las primeras palabras del subtítulo de la obra.

24 Junto con jAy, Carmela! y El cerco de Leningrado (1989-1994), Naque pertenece a la trilogía de El escenario vacio.

25 Aunque sus dos hipotextos más importantes son El viaje entretenido de Agustín de Rojas Villandrando (1603) y Esperando a Godot de Samuel Beckett (1952), Naque remite de forma más o menos explícita a muchos textos teatrales áureos, como las loas de La comedia y de Las cuatro edades del mundo, sacadas de El viaje entretenido; entremeses y autos sacramentales anónimos (como el Entremés del Capeador o el 
entre los "cómicos de la legua" auriseculares y los andrajosos zanni de la "commedia dell'arte", y a caballo entre la Espańa del XVII y la actual — se rige sobre los eternos tabúes que desatan la carcajada, es decir, el hambre, el sexo, la muerte. Por lo tanto, en una obra que versa sobre el valor de la palabra (de ayer y de hoy) y sobre el eje temático de la memoria (la memoria de la literatura, la memoria del actor, la memoria del público), el primer momento humorístico estriba, por contraste, en la negación total de la capacidad de memorizar. En efecto, los dos actores realizan unos tremendos esfuerzos mientras intentan recordar, en vano, el nombre de Lope de Vega:

RÍOs. ¿Qué?

SOLANO. ¿Cómo se llama?

Ríos. ¿Quién?

SOLANO. Ese que escribe tanto...

Ríos. No sé de quién hablas.

solano. Sí, hombre. El gran... ¿Cómo se llama?... Uno muy famoSo...

Ríos. Hay tantos...

solano. [...] Y entre todos, uno queda... el fénix de nuestro tiempo... que no ha compuesto comedia... que no mereciese estar... Ríos. Ah, sí... Ya sé quién dices. Aquel que... ¿Cómo se llama?

solano. [...] Mescua, don Guillén de Castro, Liñán, don Félix de Herrera, Valdivieso, Almendárez...

RÍos. ¡López! ¿López de...! ¿De qué?

SOLANO. ¿López?

Ríos. ¿Gómez?

SOLANO. ¿Pérez?

Auto del sacrificio de Abraham, del Códice de autos viejos), las tragedias La Seraphina (1566) de Alonso de la Vega y La gran Semíramis de Cristóbal de Virués (editada en 1609). A ellos se añaden fragmentos de cuentos folclóricos del siglo XVII, de romances viejos y de proverbios, que en su mayoría derivan del Vocabulario de refranes y frases proverbiales (1627) de Gonzalo Correas. Sobre el andamiaje expresivo de este pastiche, que imita a la perfección el estilo de sus modelos literarios y el castellano del Siglo de Oro, puede leerse Renata Londero, "Naque (1980) di José Sanchis Sinisterra: tradurre il pastiche a teatro, fra sincronia e diacronia", en Testo e traduzione. Lingue a confronto, eds. Fabiana Fusco y Monica Ballerini, Bern, Peter Lang, 2010, pp. 89-108. 
Ríos. ¿Sánchez?

SOLANO. [...] No importa ${ }^{26}$.

Más adelante, el autor funde humor e intertextualidad al citar (con variantes nimias) dos modelos áureos caracterizados por una intensa carga cómica. En la primera escena, Ríos y Solano sueltan una larga serie de paremias extraídas sobre todo del Vocabulario de refranes y frases proverbiales (1627) de Gonzalo Correas, concentrándose en las que describen las más básicas (y bufas) necesidades fisiológicas, y en las que contienen los tradicionales desencadenantes literarios de la hilaridad: la comida, las heces, el sexo, los cuernos. He aquí algunos de los más placenteros retazos de la vivaz competición refranera en la que se enredan los dos protagonistas:

SOLANO. Solo dos bocados, para engañar el hambre...

RÍos. Eso es, porque: de casada y ensalada, dos bocados y dejála.

SOLANO. Y duelos con pan, son menos. [...]

Ríos. [...] Pues el melón y el queso, tómalos a peso.

solano. [...] Y la mujer y el melón, se huelen por el pezón. [...]

Ríos. [...] Dios sea loado: el pan comido y el corral cagado.

SOLANO. Dieta y mangueta, y siete nudos en la bragueta. [...]

Ríos. [...] Al asno y al mulo, la carga en el culo. [...]

solano. [...] Mucho sabía el cornudo, pero más el que se los puso.[...]

SOLANO. No hay generación sin puta ni ladrón. [...]

solano. Por eso es aquel cornudo, porque pueden más dos que uno ${ }^{27}$.

Para la otra escena el autor elige ceñirse casi al pie de la letra al inicio del "Entremés del Capeador"28, publicado en Las comedias del famoso poeta Lope de Vega Carpio recopiladas por Bernardo Grassa (Valladolid, Juan de Bostillo, 1609) ${ }^{29}$, y salpicado de equívocos cómicos. A continuación

26 Sanchis Sinisterra, Naque-jAy, Carmela!, pp. 132-133.

27 Ibidem, pp. 145-148.

28 En Naque aparece con el título ligeramente retocado de Entremés del Bobo y el Capeador.

29 Emilio Cotarelo y Mori, Colección de entremeses, loas, bailes, jácaras y mojigangas desde fines del siglo XVI a mediados del XVIII (1911), eds. José Luis Suárez García y Abraham Madroñal, Granada, Universidad de Granada, 2000, I, p. 116. 
ofrezco el pasaje de mayor interés en este sentido, donde Solano juega el papel del bobo y Ríos el del ladrón de capas:

SOLANO. ¿Vos? ¿Y qué oficio tenéis?

Ríos. Hermano: yo soy poleo.

solano. Pues yo soy orégano, que también lo ponen en las aceitunas.

Ríos. No digo eso, hermano, sino que soy capeador.

solano. ¿Capador? Pues mire, no me cape por reverencia de Dios, que si me capa, quedaré impotente y ya no aprovecharé para nada... Ríos. Hermano, yo no os he de hacer nada. Dígoos que soy capeador, ladrón de capas... y es un oficio muy bueno porque vivimos sin trabajar $^{30}$.

El talante humorístico del texto procede de dos dilogías, construidas sobre la contigüidad semántica y fónica de las palabras que las producen: "poleo" y "capeador". El primer quid pro quo concierne a "poleo" y "orégano": en su plano referencial ambos vocablos indican dos hierbas aromáticas que tienen uso culinario. Sin embargo, el maleante/Ríos emplea "poleo" con una acepción metafórica adoptada en la jerga de la germanía:

POLEO. Lo mismo [que polinche]. [...] De pulido > polinche > poleo, hierba aromática que encubre los sabores, muy usada por su fuerte aroma, y hay un símil en la primera acepción, pues los poleos o polinches encubrían a los ladrones como el poleo encubre cualquier sabor $^{31}$.

La broma estriba en el hecho de que el bobo/Solano ignora el matiz germanesco y entiende "poleo" según su significado primario, como se colige por la ridícula respuesta que da ("Pues yo soy orégano, que también lo ponen en las aceitunas").

Finalmente, el segundo equívoco entre "capeador" y "capador" está provocado tanto por la analogía fónica que une a los dos sustantivos,

30 Sanchis Sinisterra, Naque-jAy, Carmela!, pp. 162-163.

31 María Inés Chamorro, Tesoro de villanos. Diccionario de germanía, Barcelona, Herder, 2002, pp. 669-670. 
como por la homofonía del término "capa”, que para Ríos designa el tipo de prenda de vestir que él suele robar, mientras que Solano lo interpreta como la tercera persona singular del presente de indicativo del verbo "capar".

No obstante, donde más acierta el genio humorístico y reformulador de Sanchis Sinisterra es en la parodia, género típico de las épocas de transición, y por lo tanto muy afín a un autor como él, que se precia de definirse un "epígono" 32 . A mi parecer, una de las obras donde mejor consigue reprobar un blanco favorito de su sátira -el franquismo- es "Atajo", una de las nueve piezas breves, ambientadas en los terribles años Cuarenta, que componen Terror y miseria en el primer franquismo, inspirada temática y estructuralmente en Furcht und Elend des dritten Reiches (1938) de Bertolt Brecht. Estos actos únicos se escribieron entre 1979 y 2002 y se estrenaron el 14 de noviembre de 2002 por la compañía del Teatro del Común en el Centro de Nuevos Creadores de Madrid, bajo la codirección de Sanchis e Ignasi García 33 . "Atajo", redactado y puesto en escena en 2002, es el último de los cinco textos dedicados a los partidarios de la dictadura ${ }^{34}$, mientras que cuatro más se centran en los opositores y las víctimas del régimen ${ }^{35}$. Como sostiene Milagros Sánchez Arnosi, “Atajo es una mirada ácida, corrosiva y cáustica sobre el Opus Dei" ${ }^{36}$, y en especial sobre su fundador y presidente (de 1928 a 1975), José María Escrivá de Balaguer, quien acababa de ser canonizado por Juan Pablo II cuando Terror y miseria... se representó por primera vez $^{37}$. Ya a partir del título, "Atajo”, la pluma deformadora de Sanchis

32 Cfr. Sanchis Sinisterra, "El espectador ideal", p. 50.

33 Cfr. Adela Fernández, "Terror y miseria en el primer franquismo, de Sanchis Sinisterra. Un proyecto que ilumina la memoria”, Primer Acto, 297 (2003), pp. 64-68; Renata Londero, "La historia y la cultura desde el margen: los personajes-piojos de José Sanchis Sinisterra (1979-2002)", en De élites y masas. Textualizaciones, eds. Dolores Thion Soriano Mollá y Jorge Urrutia, Madrid, Devenir el otro, 2013, pp. 361-378.

34 Los cuatro restantes son "El sudario de tiza", "Plato único", "El anillo" y "Filas prietas".

35 Se titulan "Primavera 39", "Intimidad", "Dos exilios" y "El topo".

36 Milagros Sánchez Arnosi, "Introducción", en José Sanchis Sinisterra, Terror y miseria en el primer franquismo, ed. Milagros Sánchez Arnosi, Madrid, Cátedra, 2003, pp. 9-67 (p. 59).

37 Escrivá de Balaguer fue beatificado en 1992 y canonizado en 2002 por el Papa Wojtyla. 
ataca Camino (1939), el libro de Escrivá que encierra la doctrina del Opus. Asimismo, los dos esperpénticos protagonistas de este diálogo martilleante y molesto, llevan unos nomina omina emblemáticos, que simbolizan la sed de riqueza y la estulticia, suya y de los miembros de la Prelatura: se llaman Abundio y Bolonio. Amén de remitir a la opulencia, el primer nombre aparece en el modismo "ser más tonto que Abundio", mientras que el adjetivo irónico coloquial "bolonio" significa "necio, ignorante" 38 . No es ninguna casualidad, pues, que Bolonio declare lo siguiente: "el cerebro me lo noto limpio, prístino, impoluto"39, que Abundio exhiba con orgullo su nombramiento como "Porronero Mayor Vitalicio de la Cofradía del Santo Vinagre" ${ }^{40}$, y que en un teatro como el de Sanchis - escueto, antirretórico y lindante con el silencio-, la manida verborrea de ambos avance por triviales lugares comunes y comentarios faltos de sustancia ${ }^{41}$.

De hecho, el habla artificial de los dos personajes está poblada de lemas conectados con la propaganda franquista, hipercatólica y patriótica, como la "Cruzada" ${ }^{2}$, el "muladar judeomasónico", el "republicanismo criptomarxista y afeminado" 43 , la "Europa liberal y filocomunista" ${ }^{44}$. Además, Abundio y Bolonio se explayan en pedantes enumeraciones de altisonantes vocablos, que rezuman de prefijos y sufijos pseudocultos y de extravagantes neologismos. Estos saltan a la vista cuando se describe el interior de un fastuoso edificio alusivo a la pasión de Escrivá por el lujo:
в. [...] el sitio. ¿Es un despacho, un vestíbulo, un aposento, un gabi- nete, una oficina, una delegatina, un oratorio, un condominio, un

38 Diccionario de la Real Academia Española, 23a edición, 2014 [en línea]: https://dle. rae.es (consultado el 29/12/2020).

39 Sanchis Sinisterra, Terror y miseria en el primer franquismo, p. 177.

40 En el registro coloquial, el adjetivo "porrón" equivale a "pelmazo, pachorrudo, tardo" (Diccionario de la Real Academia Española, 23a edición, 2014 [en línea]: https:// dle.rae.es (consultado el 29/12/2020).

41 "La exuberancia verbal de los personajes de Atajo contribuye a desacreditarles al contrastar con la nimiedad de lo dicho" (Sánchez Arnosi, "Introducción”, en Terror $y$ miseria en el primer franquismo, pp. 9-67 (p. 47)).

42 Ibidem, p. 166.

43 Ibidem, p. 165.

44 Ibidem, p. 168. 
archirretrete, una antecámara, un equiponderante...? [...]

A. [...] hay también un ofertorio... y un expiatorio, y un oratorio, y un refectorio, y un propiciatorio, y un locutorio, y un derogatorio, y un lavatorio, y un comulgatorio, y un conminatorio, y un flagelatorio, y un absolutorio... y hasta un fumigatorio ${ }^{45}$.

También abundan las anfibologías y los eufemismos a través de los cuales el dramaturgo subraya a nivel formal la hipocresía y la doblez de la Obra, burlándose de los orígenes humildes y del aspecto de Escrivá, de su avidez o de su obsesión con el sexo. Al contar su encuentro con el padre espiritual/Escrivá en el piso, Bolonio y Abundio lo pintan como "un baturrico [...] con gafas" ${ }^{46}$, aludiendo a su origen aragonés, y mientras espían a una sirvienta en una de sus habitaciones, notan que esta se coloca una "liga" en la pierna, antes de emprender una sesión de mortificación corporal con el propio sacerdote, a base de látigos y disciplinas. La liga, pues, remite paródicamente al cilicio que los numerarios del Opus deben llevar dos horas al día.

Para terminar, la distancia entre lo que exclama el melifluo Bolonio y la realidad encubierta detrás de la parodia se desvela en este panegírico de la "santa codicia" del "padre":

B. Fue algo conmovedor. Se interesó por mis cosas personales con una delicadeza... Que cuántas fábricas tenía, que cuál era su activo, cuál su liquidez, cuál el umbral de rentabilidad, el neto patrimonial... y que si no llevaría encima, por un casual, el libro mayor de contabilidad, para echarle un vistacillo ${ }^{47}$.

Poco después, las verdaderas intenciones de Monseñor quedan claras cuando Bolonio revela "qué clase de gente" participa en la tertulia del piso, incluso aludiendo a la presencia de Luis Carrero Blanco, gran sim-

45 Ibidem, p. 171.

46 Ibidem, p. 173. Escrivá de Balaguer nació en Barbastro, un pueblo de la provincia de Huesca, en 1902.

47 Ibidem, p. 179. Como en el caso de "baturrico", aquí también se utiliza un diminutivo coloquial, "vistacillo", con evidente intención irónica (cfr. Emilio Cascón Martín, Español coloquial. Rasgos, formas y fraseología de la lengua diaria, Madrid, Edinumen, 2000, p. 50). 
patizante del Opus y estrecho colaborador de Franco desde 1941 hasta su violenta muerte en 1973: "De lo mejor: arquitectos, abogados, banqueros, empresarios, ingenieros, sacerdotes, profesores... y hasta un almirante" ${ }^{48}$. Como capitalista que es, Bolonio ya pertenece a la cúpula y promete introducir a Abundio en ella, en un final chirriante, dominado por el rebajamiento temático típico de la parodia más agria:

B. Sobre todo, lo que se le nota es la madera de santo.

A. Todo en uno, sí señor.

B. Está bien: venga conmigo. Se lo presentaré.

A. Muchas gracias, don Bolonio.

(в). ¡Eh! ¿¿Adónde va? Que no es por ahí el refectorio... ni el preservatorio.

(A). Ya, ya. Es que necesito ir primero al mingitorio... ${ }^{49}$.

Si en las tres obras que acabo de analizar el autor dirige su mirada agridulce al pasado, más o menos lejano, aunque siempre vigente en la memoria individual y colectiva, en las últimas dos que voy a considerar campea un presente problemático y desalentador, cuyas lacras también denuncian otros dramaturgos espańoles militantes de la generación de Sanchis, como José Luis Alonso de Santos, Jerónimo López Mozo, Josep Maria Benet i Jornet e Ignacio Amestoy. Puesto que el escenario funciona como un poderoso altavoz apto para amplificar cuestiones actuales candentes - la incomunicabilidad ${ }^{50}$, la industria armamentística $^{51}$, el desempleo ${ }^{52}$, la escasa atención de ciertos gobiernos por la cultura ${ }^{53}$, la prepotencia del mercado financiero ${ }^{54}$, la desigualdad social ${ }^{55}$ - , el acre humor de Sanchis

48 Ibidem, p. 180.

49 Ibidem, p. 182.

50 Es el tema de la pieza breve Vidas privadas (2000), uno de los 21 Textículos recogidos en Vacio y otras poquedades, Madrid, La Avispa, 2003.

51 El argumento se trata en Misiles melódicos (2004-2005), que comentaré a continuación.

52 A este problema remite, como veremos, Vagas noticias de Klamm (2009).

53 Cfr. Vitalicios, compuesta en 2010 pero estrenada por la agencia de servicios culturales EscénaTe el 20 de febrero de 2014, en la Sala Mirador de Madrid.

54 Cfr. la "comitragedia" Bartolomé encadenado, estrenada en el Teatre Grec de Barcelona el 18 de julio de 2014.

55 Pienso en El lugar donde rezan las putas o Que lo dicho sea, texto estrenado con la 
"no viene a traer la comodidad al espectador", sino que quiere "pedirnos un mundo en el que lo posible sea real" 56 . Entre los varios textos que podría traer a colación, escojo por su originalidad Misiles melódicos — redactado en 2004 y puesto en escena por primera vez el 15 de abril de 2005 en el Teatro Principal de Zaragoza, con la dirección de David Amitin y música de Gabriel Sopeña_, y Vagas noticias de Klamm, escrito en 2009 y estrenado el 25 de junio de ese mismo año en la Sala Beckett de Barcelona, bajo la dirección de Sanchis Sinisterra.

Misiles melódicos forma parte de la "trilogía de las artes", que también integran El lector por horas (1996-1999) ${ }^{57}$ y La raya del pelo de William Holden (1998-2001) ${ }^{58}$, porque si los dos últimos dramas homenajean la literatura y el cine, el primero versa sobre la música, pero de manera muy irónica. Esta "tragicomedia musical" lleva un subtítulo que suena serio y bizarro a la vez, por su guińo al rótulo institucional que envuelve las cajetillas de tabaco: "Las autoridades sanitarias no advierten de que las armas perjudican seriamente la salud". La sala, pues, ya se entera de que se hablará de un asunto para nada ligero - las armas - , aunque este se inserta en una trama jocoso-grotesca acompañada por una banda sonora insólita e insistente, pero humorística, como en 2005 subrayó el mismo Sanchis, elogiando al músico Gabriel Sopeña: "Y si me considero afortunado por haber puesto mi obra en manos de un compositor que, en tanto que poeta y cantante, sabe potenciar y colorear magistralmente el diálogo teatral, también el público puede gozar del raro privilegio de escuchar una música dotada de sentido del humor"59.

El canto y la música conforman el telón de fondo de toda la estrafalaria acción, que muestra a Javier Zulueta - un cínico productor de ar-

dirección del propio Sanchis en la Sala Margarita Xirgu del Teatro Espańol de Madrid, el 15 de marzo de 2018.

56 Itziar Pascual, "Un modo de contemplar la realidad", en José Sanchis Sinisterra, Misiles melódicos - Vitalicios, ed. Itziar Pascual, Madrid, Publicaciones de la Asociación de Directores de Escena de España, 2016, pp. 7-26 (p. 15).

57 Se compuso en 1996 y su estreno se produjo en el Teatre Nacional de Catalunya (Barcelona) el 21 de enero de 1999.

58 Compuesta en 1998, la obra se llevó al escenario el 19 de enero de 2001 en el Teatro Palacio Valdés de Avilés.

59 “Misiles melódicos”, en José Sanchis Sinisterra, El texto insumiso. Nuevos fragmentos de un discurso teatral, ed. Esther Lázaro, Ciudad Real, Naque, 2018, p. 165. 
mas destinadas a los países más pobres y guerreros del mundo- aquejado por una misteriosa enfermedad faríngea que le impide hablar sin emitir coplas cantadas, hasta cuando, agotado por su afección y arrepentido, decide empezar a fabricar "bienes de uso civil""60. A la redención del protagonista sigue el apoteósico cierre caricaturesco de la pieza, concebido como el happy ending de un musical de Broadway. La voz de la deuteragonista Jessica, joven y sensual traficante de armas, junto con la acotación conclusiva, anuncian un triunfal coup de théâtre: el ingreso ruidoso y rocambolesco del Séptimo de Caballería" al ritmo de "un brillante número orquestal' 62 .

Del amargo divertimento en que consiste Misiles melódicos se pasa a la atmósfera kafkiana y surreal de Vagas noticias de Klamm, representada y editada en $2009^{63}$. En el artículo "Trece notas para definir 'lo kafkiano'”, Sanchis evidencia algunos rasgos de la producción de Kafka -uno de sus autores modélicos-, que también se reconocen en Vagas noticias de Klamm:

Una clase de humor que asocia inextricablemente lo cómico y lo siniestro [...]. Una galería de personajes (generalmente empleados y comerciantes) de conciencia limitada, obsesiva y a menudo paranoide, que se relacionan torpemente, inadecuadamente, con su entorno, $[. .$.$] estableciendo unos vínculos interpersonales desajustados,$ asimétricos, utilitarios y, en suma, insatisfactorios [...]. Un marco espacial inaprehensible por su vaguedad e imprecisión ${ }^{64}$.

En el programa del primer montaje barcelonés, además, el autor se pregunta si "es lícito reírse del paro", un problema acuciante en la España de hoy que constituye el foco argumental de la obra. A continuación,

60 Sanchis Sinisterra, Misiles melódicos - Vitalicios, p. 112.

61 La referencia a este famoso regimiento de caballería del ejército estadounidense, activo desde las guerras de finales del siglo XIX contra los nativos americanos hasta la Guerra del Golfo (1990-1991), quizá se deba al recuerdo de las películas del oeste que lo idealizaron (como la de 1956, dirigida por Joseph H. Lewis), o bien de su conocida marcha militar irlandesa, apodada "Garryowen".

62 Sanchis Sinisterra, Misiles melódicos - Vitalicios, p. 113.

63 Sanchis Sinisterra, Vagas noticias de Klamm, Tarragona, Arola Editors, 2009.

64 En Sanchis Sinisterra, La escena sin límites, pp. 107-108 (p. 107). 
compara al "parado" con otros "náufragos" sociales — tan numerosos en su dramaturgia - y ofrece una nómina de personajes literarios o cinematográficos miserables, parodiados por sus autores, tales como el viejo Arnolphe de L'école des femmes de Molière (1662), el don Friolera valleinclaniano ${ }^{65}$, los mendigos de Die Dreigroschenoper de Brecht (1928) y Charlot. Por último, sugiere: "es posible que la risa, más a menudo de lo que creemos, sea el último reducto de la compasión. O de la rabia"66.

Efectivamente, en Vagas noticias de Klamm el dramaturgo esconde su indignación por el perdurar crónico del desempleo en su país detrás de una máscara cómica y paradójica: la protagonista femenina, Carolina Repullo, se somete a una extraña entrevista de trabajo en la empresa de un tal señor Klamm, eminencia gris e invisible. Los dos enigmáticos y desagradables interlocutores de Carolina, el director de la Sección de Recursos Humanos, Señor Valverde, y su ayudante Gelmírez, examinan con ella su estrambótico currículum —un conjunto de los oficios más diversos- y le imponen que simule con ellos situaciones laborales humillantes, como la cena con un reticente ejecutivo japonés o el coloquio con un cliente furioso, insatisfecho con el piso que la chica acaba de venderle. A la rareza del contexto y de los personajes se corresponde un discurso lleno de divertidos malabarismos verbales y secuencias graciosas. Por ejemplo, para justificar por qué ha trabajado solo dos días en una compañía aérea, Carolina afirma que era "muy volátil" y que "quebró en el vuelo de inauguración" ${ }^{67}$. Y cuando Gelmírez arroja una intempestiva cita en latín, Carolina disfraza su ignorancia con una risible escusa:

GELMÍREZ: Aliorum indicio permulta nobis et facienda et non facienda et mutanda et corrigenda sunt.

SR. VALDERDE: Exacto. ¿Comprende, señorita?

CAROLINA: Así, así... Es que los idiomas, ¿verdad?, de no practicarlos, se olvidan... ${ }^{68}$.

65 Cfr. el célebre esperpento Los cuernos de don Friolera (1926), de Ramón del Valle-Inclán.

66 Sanchis Sinisterra, El texto insumiso, p. 169.

67 Sanchis Sinisterra, Vagas noticias de Klamm, p. 34.

68 Ibidem, p. 43. 
Una pieza donde la ambigüedad y la contradicción sobresalen, en línea con Kafka y Beckett, puede concluir solo con un "Epílogo"69 desconcertante. Como precisa la acotación, una vez terminada la entrevista, "el escenario se parte en dos. A un lado permanece un segmento del espacio anterior. En el otro, débilmente iluminado, se insinúa un modesto y minúsculo apartamento de una sola pieza"70. Por un lado vemos a Valverde y Gelmírez en su despacho, destruyendo el currículum de Carolina, a la que consideran inadecuada para el puesto en la empresa, y haciendo disparatadas inferencias sobre los actos y los proyectos del indescifrable Klamm. Y por otro Carolina ha regresado a su casa, donde se transforma en la provocativa "Lolita Bananas" a la espera de supuestos clientes clandestinos: se ducha, se atavía con "ropa interior entre infantil y erótica" 71 , "un vestido infantil muy provocativo" y "una peluca con trenzas"72, y recibe dos llamadas, la de su madre y la de un tal Stefan, probablemente el novio que la ronda. A ambos Carolina/Lolita, culpable por haberse inventado "los títulos y diplomas"73 del curriculum, asegura que ha encontrado trabajo en el "Oligopolium" de Klamm...

Como espero que se haya podido comprobar a lo largo de este breve análisis de cinco obras relevantes, compuestas a lo largo de más de veinte años (1987-2009) de la extensa y fructífera actividad teatral de José Sanchis Sinisterra, la sonrisa irónica, la risa paródica o la mueca sarcástica se asocian a la memoria de un pasado henchido de abusos y violencias (el siglo XVII en Naque, la Guerra Civil en ;Ay, Carmela!, el franquismo en Atajo) o están suscitadas por la reflexión sobre un presente plagado de impiedad e indiferencia (Misiles melódicos, Vagas noticias de Klamm). El humorismo del dramaturgo siempre apela a un auditorio despierto y librepensador, que se comprometa a "rellenar los huecos" 74 del sentido y del discurso, tan abundantes en un mundo inexplicable y caótico. Sanchis consigue su objetivo manejando con maestría una vez más la única herra-

69 Ibidem, pp. 73-84.

70 Ibidem, p. 73.

71 Ibidem, p. 81.

72 Ibidem, p. 84.

73 Ibidem, p. 77.

74 Sanchis Sinisterra, "Dramaturgia de la recepción” (1995), en La escena sin límites, pp. 249-254 (p. 253). 
mienta de la que dispone para incidir en la realidad: la palabra. Una palabra que hace pensar y sonreír, que oculta en vez de mostrar, una palabra donde repercuten la incongruencia, el misterio y los caprichos de un hado inabarcable. Una palabra, en suma, hacia la que se alargan y resuenan las sombras y los silencios que nos habitan.

Entre calladas brumas también camina Francisco Goya, refugiado en Francia en el ocaso de su vida. Viejo, sordo, desarraigado, pero aún genial e inquieto: así lo imagina el autor en Monsieur Goya (Una indagación) $(2019)^{75}$, en la que el espectador solo puede escuchar la voz en off del artista sin verlo, mientras pinta La lechera de Burdeos (1827-1828) y llena de dibujos los álbumes $G$ y $H$, al tiempo que conversa con la amada Leocadia y sus hijos Guillermo y Rosario, o con el amigo Leandro Fernández de Moratín. El de Sanchis es un Goya borroso y fantasmal pero sabio, así como fantasmal, borrosa e inteligente es la muerta Carmela que desde el más allá se le aparece a su incrédulo Paulino. Figuras liminares, translúcidas, sí, pero cuya mente sigue honda y viva. Al igual que el humor, donde la lágrima se esfuma en la risa, y viceversa; al igual que la ironía, forma sutil de equidistante sabiduría que continuamente incita al dinamismo del pensamiento y de la conciencia ${ }^{76}$.

75 Se estrenó el 19 de septiembre de 2019 en el Teatro Fernán Gómez de Madrid, con la dirección de Laura Ortega. En el mismo año la obra fue publicada por la editorial Naque de Ciudad Real, con prólogo de Sara Núñez de Arenas.

76 Jankélévitch, op. cit., p. 41, se pregunta retóricamente: “¿Y si la ironía fuese uno de los rostros de la sabiduría?". 